\title{
A dinâmica da taxa de câmbio face às operações swap no Brasil (2002-2015): uma interpretação pós-keynesiana
}

The exchange rate dynamics facing swap operations in Brasil (2002-2015): a post-keynesian approach

\author{
Leandro Vieira Lima Araújo (1) \\ Fábio Henrique Bittes Terra (2) \\ (1) Universidade Federal do Rio Grande do Sul \\ (2) Universidade Federal do $\mathrm{ABC}$
}

\begin{abstract}
Based on the Post-Keynesian theory, we investigate the relationship between the Brazilian Real exchange rate behavior and the Brazilian Central Bank swap interventions over 2002-2015. Initially, we analyze open market economy properties and present theoretical propositions on the exchange rate determination, highlighting features of the Brazilian foreign exchange market and of Brazil's position in the international monetary system. Then, we undertake empirical exams on the nominal and real-effective exchange rates determination using two statistical methods. In order to measure the volatility of the mentioned exchange rates, we estimate $\mathrm{ARCH} /$ GARCH models, which reported volatility during 2002-2015. Furthermore, to measure the variance of exchange rates in relation to swaps, we estimate a VAR model. The relationship found is that swaps are responses to the behavior of the nominal exchange rate, although its effects are more noticed on the real effective exchange rate.
\end{abstract}

\section{Keywords}

swaps; exchange rate; Keynes; post keynesian theory.

JEL Codes C51; E12; F31.

\section{Resumo}

Investiga-se, à luz da teoria pós-keynesiana, o comportamento da taxa de câmbio no Brasil face as intervenções com swaps cambiais do Banco Central de 2002 a 2015. Analisam-se as propriedades de uma economia aberta, as condicionantes da taxa de câmbio, o mercado cambial e a inserção do Brasil no sistema monetário internacional. Afere-se empiricamente o comportamento cambial frente às operações swap por meio de modelos ARCH/GARCH e VAR. Com os primeiros, observa-se a volatilidade das taxas de câmbio nominal e real efetiva, cujos resultados apontam presença de volatilidade no periodo. Em seguida, realizam-se estimações $V A R$, para estudar a variância das taxas de câmbio ante os swaps e variáveis relevantes ao comportamento cambial, concluindo-se que os swaps são respostas ao comportamento da taxa de câmbio nominal, embora seus efeitos são mais visiveis sobre a taxa de câmbio real efetiva.

\section{Palavras-chave}

swaps; taxa de câmbio; Keynes; teoria pós-keynesiana.

Códigos JEL C51; E12; F31. 


\section{Introdução}

A taxa de câmbio em países emergentes, como o Brasil, é caracteristicamente volátil, pois está sujeita a mudanças - de nível e ao redor dele - em curtos espaços de tempo. As razões residem, em âmbito geral, sobre a posição que estes países ocupam no sistema monetário e financeiro internacional, em que suas moedas são ativos com menor liquidez e, portanto, são menos demandadas quando há maior preferência pela liquidez e fuga para qualidade. Em momentos de maior ânimo e redução de incerteza, a demanda por elas se amplia, por conta dos retornos mais elevados que oferecem aos seus detentores. Porém, como se sabe, não apenas a decisão de composição de portfólio determina a taxa de câmbio dos países emergentes. Também o lado real do setor externo define o fluxo de divisas entre os países. Neste particular, a teoria pós-keynesiana entende que a inserção dos emergentes na corrente de comércio mundial é subalterna, com defasagem tecnológica entre aquilo que exportam e importam, implicando desvantagens nos termos de troca e na geração de dólares próprios, importante variável para composição de reservas cambiais menos vulneráveis.

Além dos fluxos real e monetário-financeiro, outro determinante do comportamento da taxa de câmbio é a autoridade cambial e, por consequência, a política cambial adotada no país. No Brasil, percebem-se duas formas de condução da política cambial após a estabilização inflacionária de 1994. Por um lado, houve até 15 de janeiro de 1999, o regime de câmbio fixo, peça-chave na estabilização monetária auferida com o Plano Real. Desde lá, no entanto, o Brasil pratica, de jure, regime cambial flexível, porém, de facto, há intervenções da autoridade cambial no mercado de câmbio, tanto na forma de regulamentações colocadas sobre o funcionamento do referido mercado, quanto via busca de construção de estabilidade na dinâmica da taxa de câmbio, principalmente via swaps cambiais.

Os swaps buscam, sobretudo, oferecer hedge cambial aos agentes no mercado de câmbio e, então, influenciar a oferta e a demanda dos contratos cambiais, à vista e a prazo. Por um lado, uma variação na taxa de câmbio influencia diretamente o passivo dos agentes, o que os faz recorrer aos swaps para se protegerem dos riscos inerentes à variação cambial. Por outro lado, o comportamento instável da taxa de câmbio é uma preocupação da autoridade monetária, por ser o câmbio um preço crucial para o comportamento de variáveis macroeconômicas, como a inflação, a estabi- 
lidade financeira macroeconômica, o equilíbrio do balanço de pagamento, dentre outras. Isso justifica o Bacen ofertar os swaps para tentar controlar a taxa de câmbio em um nível que julga estável.

Neste contexto, o objetivo deste artigo é estudar a dinâmica da taxa de câmbio no Brasil pós-2002, quando as intervenções da autoridade cambial, o Banco Central do Brasil, no mercado cambial, via utilização dos swaps cambiais, passou a ser mais intensa. A pergunta norteadora é, como responde a taxa de câmbio, nominal e real efetiva, às operações swap? A resposta à questão será dada via utilização de instrumentais econométricos Auto-Regressive Conditional Heteroscedastic (ARCH) com a finalidade de se mensurar, primeiramente, a volatilidade cambial. Após isso, por meio dos Vetores Autorregressivos, investigam-se os principais condicionantes real e financeiro da dinâmica cambial, medindo qual o impacto dos swaps na dinâmica cambial entre janeiro de 2002 e setembro de 2015.

Este artigo conta com 4 seções, além desta introdução das conclusões finais. Na seção 2, será modelada a decisão de investimento em uma economia monetária da produção aberta, meio pelo qual se explicará como o capital, sobretudo financeiro, trafega entre os países. Na seção 3, são reportados os condicionantes da taxa de câmbio, a bem de se realizar a especificação teórica das variáveis analisadas no modelo econométrico. $\mathrm{Na}$ seção 4, a atuação do Banco Central do Brasil, como autoridade cambial do país, é analisada, momento em que as operações swap serão explicadas, completando o quadro dos fatores condicionantes da dinâmica da taxa de câmbio no Brasil. A seção 5 realizará os testes empíricos, por meio de modelos ARCH, GARCH e VAR.

\section{0 cenário keynesiano: a tomada de decisões em uma economia monetária aberta}

A economia monetária de produção é a forma pela qual Keynes (1996) conceituou o sistema capitalista. Para o autor, a lógica do sistema centra-se no comportamento do empresário, pois é o investimento que ele faz que cria emprego, renda e riqueza. Neste particular, a não neutralidade da moeda e as diferentes razões para se demandá-la são, fundamentais para que compreenda a tomada de decisões dos empresários. 
De acordo com Keynes (1996), três motivos ${ }^{1}$ que justificam a demanda por moeda: (i) motivo transação; (ii) motivo precauçãó2 e, (iii) motivo especulação. Será a preferência por maior ou menor volume de liquidez vis-à-vis a especulação sobre os níveis atual e futuro (este, expectacional) dos juros que explicará se os agentes reterão moeda, ativos financeiros ou bens de capital. Tenha-se claro, portanto, o papel das expectativas para Keynes (1996) e, ademais, da moeda como ativo que funciona como reserva de valor e, sobretudo, fornecedor de segurança em momentos que a incerteza conduzir à maior preferência pela liquidez. Dessa forma, a demanda por ativos depende de atributos tais como as expectativas dos investidores, os custos de carregamento, as possibilidades de ganhos ou perdas de capital e, por fim, da liquidez do ativo. Juntos esses atributos precificam uma taxa de retorno específica a cada ativo. Por fim, este retorno determina a formação de carteira de ativos dos agentes.

No contexto da tomada de decisão, Harvey (2009a) argumenta que os agentes, para tomarem suas decisões, formulam modelos mentais, que são produtos sociais, formados por conceitos individuais e por fatores psicológicos julgados como factíveis para elaboração de previsões e para a concepção da ação a ser tomada. Nesta perspectiva, incerteza, convenção, estados de confiança e o espírito animal, elemento presentes em Keynes (1996) são também apreendidos por Harvey (2006). ${ }^{3}$

Nestes modelos mentais (HARVEY, 2006, 2009a, 2009b; KEYNES, 1996), os elementos psicológicos são aspectos especiais da discussão de volatilidade dos preços das moedas. A incerteza faz os agentes considerarem pesos desproporcionais entre os eventos e a representatividade estimula a realização de previsões baseadas em pequenas amostras (HARVEY, 1991). Por isso, a precificação de ativos pode conduzir à escolha da moeda como uma variável não aleatória na alocação de investimentos, inclusive

1 Em Keynes (1937), um quarto e último motivo para a demanda por moeda, o finance, reflete a necessidade de moeda para financiar algum dispêndio planejado, principalmente investimento.

2 Decorre da presença de incerteza e, consequentemente, de expectativas, características das economias monetárias da produção. A existência de expectativas formadas pela existência da incerteza introduz a lógica da preferência pela liquidez, ou seja, o desejo ou não de reter moeda.

3 Harvey (2009a) argumenta que o processo de tomar uma decisão é realizado em cinco estágios: (i) análise de eventualidade; (ii) definição da escolha e consequência; (iii) ponderação da decisão; (iv) escolha; e (v) análise do pós-evento. Durante cada etapa, a tomada de decisões baseia-se em princípios heurísticos que auxiliam as previsões, são eles: disponibilidade; representatividade; ancoragem; sabedoria convencional e enquadramento 
os ativos estrangeiros. Assim sendo, a taxa de câmbio pode, portanto, ser um objeto de interesse para a especulação.

Para Harvey (2009a), as transações nos mercados cambiais são um condicionante fundamental do comportamento da taxa de câmbio e elas são diretamente afetadas por expectativas, de curto e de médio prazos. As últimas, por serem menos voláteis, são mais robustas, enquanto que as primeiras são mais suscetíveis a variações súbitas e a transformações conjunturais. A taxa de câmbio corrente, então, é função dos valores futuros esperados de curto e médio prazos, alterando-se à medida em que as expectativas sejam reavaliadas.

$$
E_{t}=f\left[\left(E_{t+n}^{e}-E_{t-1}\right),\left(E_{t+m}^{e}-E_{t-1}\right)\right]
$$

Ainda segundo Harvey (2009b), o mercado cambial é principalmente determinado pelos fluxos de capitais financeiros; não obstante, o comércio e investimento direto externo também possuem impactos sobre a moeda estrangeira, embora secundários. Quando os participantes dos mercados financeiros ${ }^{4}$ acreditam que a moeda estrangeira se valorizará relativamente à moeda doméstica, eles comprarão aquela; se os demais agentes seguirem esta ação, uma apreciação de fato acontecerá. Desta forma, a questão que o modelo mental de Harvey (1991, 2009a) busca responder é: o que levaria os agentes a acreditarem inicialmente nesta apreciação?

A priori, existem três razões para compra moeda estrangeira: comércio externo; investimento direto externo e carteira de investimentos financeiros. Os agentes sabem que eles podem fazer dinheiro, não por esperarem que estes canais afetem a taxa de câmbio, mas por serem capazes de agir antecipando os eventos que conduzam aos efeitos destes canais. Assim, quando uma nova informação sugere, por exemplo, que os fluxos de investimento direto podem ser alterados, o impacto é imediato e não apenas sobre o investimento direto, mas sobre o mercado financeiro, uma vez que os agentes ajustarão suas carteiras para posicionarem-se e tirarem proveito do movimento previsto (HARVEY, 2009b).

Além disso, as previsões dos participantes no mercado são tendenciais, isto é, um elemento que pode ser considerado um importante fator para a

4 Harvey (1991) aponta que, na determinação da taxa de câmbio, os agentes se modificaram ao longo das décadas, pois negociadores, bancos, multinacionais entre outros agentes passaram a ter maior influência no comportamento cambial. 
tomada de decisão em um período pode ser ignorado no próximo e vice-versa. Embora aspectos especulativos, representados pelos fluxos financeiros apresentem resposta da taxa de câmbio com maior velocidade, em razão de sua volatilidade frente à mudança de expectativas, os fluxos comerciais também afetarão, e serão afetados, pela taxa de câmbio e pela própria dinâmica financeira em um momento seguinte. Esse é um efeito de retroalimentação entre as diferentes categorias de fluxos internacionais e a taxa de câmbio, mas que se afetam em diferentes temporalidades.

Em síntese, para Harvey (2009b), a tomada de decisões em uma economia aberta dependerá, portanto, da taxa de câmbio corrente e da esperada, cujas variações refletem justamente as alterações nas posições especulativas dos próprios agentes que atuam nos mercados cambiais, mais do que refletem mudanças nos padrões de comércio entre os países. Não obstante, há outros fatores frequentes que impactam decisões e, logo, afetam a taxa de câmbio e a alocação internacional do investimento. Entre eles, apontam-se: taxas de juros domésticas relativas às do resto do mundo, crescimento, emprego, investimento, inflação, fluxos comerciais, indicadores de risco, a oferta de moeda, entre outros.

No âmbito dos fluxos internacionais de capitais, há o aspecto de hierarquia das moedas, resultado das assimetrias existentes no Sistema Monetário Financeiro Internacional (SMFI). Condicionantes econômicos e políticos do SMFI definem distintas qualidades às moedas, conferindo diferentes capacidades de elas exercerem suas funções em âmbito internacional, com pior inserção nas economias emergentes. Resultam-se em diferentes demandas por moedas, como também em desiguais fluxos de capitais entre os países, fruto dos níveis distintos da hierarquia do $\mathrm{SMFI}^{5}$ (CONTI et al., 2014). Por fim, esta dinâmica hierárquica dos SMFI é reforçada e explorada pelos agentes na economia monetária da produção, com o objetivo de aumentar os seus lucros.

\section{Os condicionantes da taxa de câmbio: a especifica-}

5 Além disso, para Prates (2005), a assimetria do SMFI possui duas dimensões. A primeira refere-se aos determinantes dos fluxos de capitais voltados a economias emergentes, cuja dinâmica lhes é exógena. Isso faz com que suas vulnerabilidades sejam maiores, por mudanças na fase do ciclo econômico, na política monetária dos países centrais, e por conta das diferentes preferências pela liquidez dos investidores. A segunda assimetria refere-se à inserção marginal dos países periféricos nos fluxos de capitais. 


\section{ção teórica do modelo econométrico}

As trocas de moedas ocorrem no interior do mercado financeiro, especificamente no mercado cambial. Como todo mercado, este também é constituído por regulamentações e intervenções da autoridade monetária, que definem o modo pelo qual os agentes podem nele ser comportar. Neste sentido, a institucionalidade do mercado cambial também é variável a ser descrita para se compreender o comportamento da taxa de câmbio. A Figura 1, abaixo, ilustra a dinâmica pela qual a taxa de câmbio se forma.

Os lados real e financeiro das transações internacionais têm seu ponto de encontro no sistema financeiro de um país, especificamente no seu mercado cambial. Neste processo, destacam-se os diversos segmentos do mercado cambial e como estes interagem com os condicionantes da taxa de câmbio. Segundo Rossi (2012), o processo de determinação do câmbio decorre da interação entre os agentes econômicos no âmbito da institucionalidade do mercado de câmbio. Dentre estes agentes, por fim, está o Banco Central do Brasil (Bacen), que é capaz de modificar a liquidez do mercado e, assim, afetar a taxa de câmbio.

Por um lado, há os condicionantes vindos do mercado de bens e serviços, das relações comerciais e dos fluxos de divisas da esfera real da economia, em boa parte sintetizados nos resultados da conta de transações correntes do balanço de pagamentos (BP). Por outro lado, há também determinantes do mercado financeiro, como investimentos produtivos, transferências intercompanhias, derivativos e outros instrumentos financeiros. Portanto, a taxa de câmbio resulta de diversos fatores que condicionam os fluxos reais e financeiros acima descritos, tais como o diferencial de juros nacional e internacional, das elasticidades no comércio internacional, do nível de preços e suas decorrências tanto sobre o comércio entre os diversos países quanto sobre as políticas adotadas pela autoridade monetária de cada país, além de fatores microeconômicos do mercado de câmbio (que compreendem as instituições, os agentes, a atividade especulativa, os mecanismos regulatórios e os canais de arbitragem entre os diferentes mercados). Cabe notar que estes elementos revelam que variações em condições subjetivas dos indivíduos, por exemplo, a propensão a consumir e a disposição do empresário ao investir, e em fatores objetivos, como renda, os salários e lucros, afetam o consumo, os investimentos, a demanda externa e, por fim, a taxa de câmbio (GALA e LIBÂNIO, 2011). 


\section{Figura 1 Formação da taxa de câmbio}

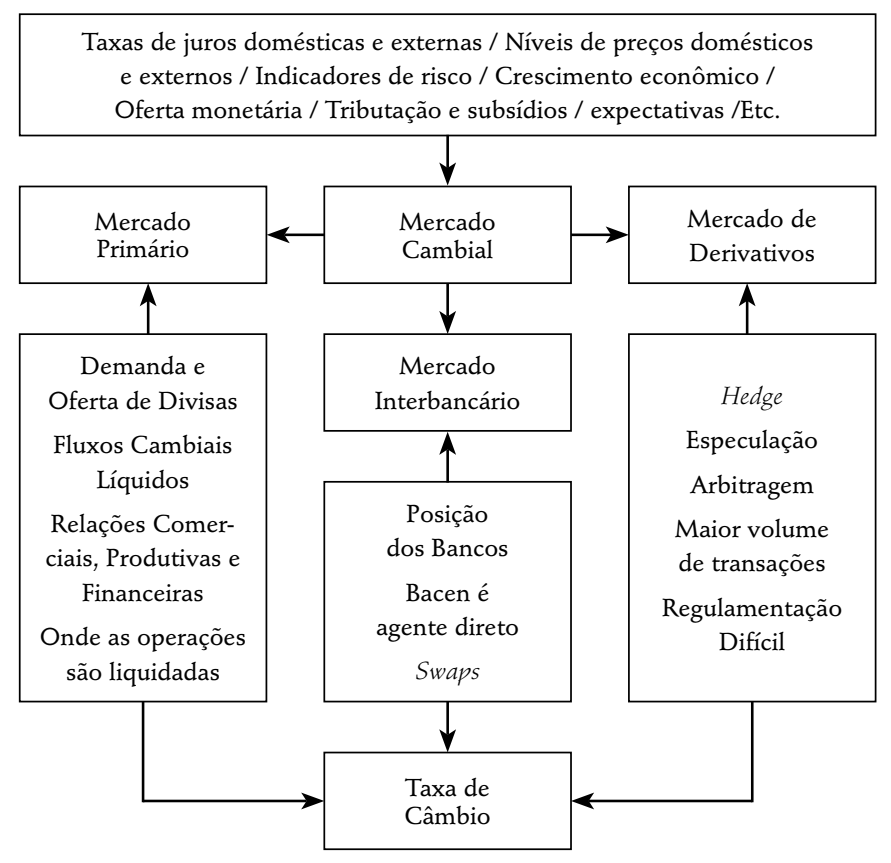

Fonte: Elaboração própria.

As moedas nacionais são ativos financeiros cuja precificação e detenção pelos investidores financeiros estrutura-se assimetricamente, em função da hierarquia das moedas no SMFI e do ciclo de liquidez internacional. ${ }^{6}$ As condições que guiam os investidores a buscarem por ativos financeiros são submetidas às expectativas dos agentes em suas transações especulativas sobre variáveis futuras, principalmente juros e câmbio. Por essa razão, o apoio em referências de riscos feitas por agências de rating afeta a aquisição de ativos internacionalmente e, assim, também impactam o comportamento cambial. Neste sentido, surgem os chamados Risco-País, para auxiliar os investidores em suas decisões de composição de portfólio.

Outro fator a ser analisado para analisar-se a dinâmica da taxa de câmbio é inflação. Ela afeta o câmbio por meio de suas pressões sobre a taxa 6 Rossi (2012) acresce ainda a extensão das operações carry trade, que oportuniza a transmissão do ciclo de liquidez para o câmbio. Sua operação refere-se a um investimento intermoedas que forma tanto uma posição vendida - passivo - em moeda de baixa taxas de juros quanto uma posição comprada - ativo - em moedas com taxas de juros elevadas. Para o autor, a generalização dessa operação confere características específicas à dinâmica cambial. 
de câmbio real. Os movimentos na taxa de câmbio podem ser amenizados pela política monetária e também pela taxa de câmbio nominal, cuja política cambial pode tentar administrar, a depender do conjunto de reservas internacionais que o país possuir. Variações no câmbio real, por sua vez, repercutem sobre o comércio exterior do país que, retroativamente, influenciará o câmbio nominal.

Outros dois fatores relevantes na análise do câmbio são o passivo externo líquido (PEL) e a posição internacional dos investimentos (PII) ${ }^{7}$. Sob este ponto de vista, pode-se mensurar o impacto macroeconômico futuro dos ativos e passivos externos sob a formação da dívida líquida externa e, consequentemente, sob o comportamento da taxa de câmbio (CYSNE, 2008). A taxa de câmbio, portanto, é influenciada pelos estoques de ativos e passivos externos e consequente exposição deles às variações cambiais e às flutuações dos seus preços, que implicam possíveis ganhos ou perdas de capital.

A taxa de câmbio se forma no mercado de câmbio, o locus de realização das operações cambiais entre os agentes autorizados pelo Bacen e os demandantes e ofertantes de moeda estrangeira. Nele, há três segmentos mercado: primário; interbancário; e de derivativos onshore e offshore ${ }^{8}$. O mercado primário é o segmento do mercado cambial em que ocorrem os fluxos referentes às relações comerciais e financeiras de agentes primários, ou seja, exportadores, importadores, turistas e investidores estrangeiros e internacionais, tomadores de recursos no exterior ou credores nacionais de tomadores no exterior, etc. É neste mercado que a maioria das operações de câmbio são liquidadas e que a oferta e a demanda de residentes e estrangeiros se encontram, dando acesso à moeda nacional ou estrangeira.

O mercado interbancário é onde as posições dos bancos residentes são niveladas, isto é, um banco negocia com outro para ajustar sua posição de câmbio quando, no mercado primário, incorreu em vendas ou compras além do necessário. O mercado interbancário "pode ser descrito como o lócus da negociação do estoque de divisas entre as instituições que podem carregar posições de câmbio" (ROSSI, 2012, p. 103). Então, embora os flu-

7 Ao discutir dívida externa líquida, Cysne (2008) prioriza o PEL sob a ótica do PII e não o cálculo pelo déficit acumulado do BP. O argumento é que o primeiro capta - e o outro não - valorizações e desvalorizações de ativos e passivos, monetizações de ouro, alocações, cancelamentos de direitos especiais de saque, além de apresentar maior elasticidade.

8 Essa adjetivação é feita com para diferenciar o espaço de negociação de reais de sua jurisdição. Para mais, Rossi (2012). 
xos de divisas, sejam eles comerciais ou financeiros, façam-se primordiais para a formação do câmbio, os bancos, ao ajustarem suas posições individualmente, podem também ser condicionantes da taxa de câmbio. Há situações em que há depreciação do real mesmo com entrada líquida de dólares, cuja causa é a atuação dos bancos, ao se inserirem na dinâmica assumindo uma posição cambial comprada. Isto é, as divisas nos mercados primário e interbancário são disputadas por bancos que estão dispostos a pagar melhor pela moeda em negociação, o que leva à depreciação do real. Assim, se os bancos querem variar seu estoque de divisas, isso repercutirá em mudanças no câmbio.

O papel dos bancos também afeta o mercado primário, uma vez que pressionam os preços da moeda quando tomam estratégias referentes à posição que pretendem assumir. Rossi (2012) sintetiza os fluxos cambiais atrelados à dinâmica do mercado interbancário por meio da equação a seguir, que formaliza, no período $t$, a relação entre o fluxo cambial contratado, $F C_{t}$, a variação da posição comprada em dólares dos bancos $\left(\triangle P B_{t}\right)$, e as intervenções do Bacen no mercado à vista $\left(I_{t}\right)$. O termo $A_{t}$ é uma variável de ajustes. Logo, a equação que apresenta estes fluxos cambiais no período $t$ é assim descrita,

$$
F C_{t}=I_{t}+\Delta P B_{t}+A_{t}
$$

Portanto, o fluxo cambial, restrito ao mercado interbancário, tem parte importante de sua composição explicada pelas posições dos bancos, que são impactadas diretamente nas decisões de compra e venda da autoridade monetária. Ou seja, se o Bacen compra mais moeda estrangeira do que o fluxo cambial, a posição vendida dos bancos aumenta necessariamente. Neste caso, as negociações à vista dos bancos não representam uma estratégia especulativa; ademais, deve-se entender que a ação deles frente a expectativas de valorização ou desvalorização reflete-se mais numa variação da taxa de câmbio do que nas suas posições compradas. Isto é, os bancos são passivos em relação à quantidade vendida ou comprada quando se pensa em um conjunto pois suas posições dependem da oferta e demanda dos clientes e da autoridade monetária (SOUZA e HOFF, 2006, p. 23).

O mercado de derivativos, por fim, desempenha um papel dual. Por um lado, ele fornece hedge, reduzindo as incertezas sobre variações de preços e fornecendo liquidez para operações arriscadas. Por outro lado, ele tem 
o potencial de aumentar as instabilidades macroeconômicas, pois permite a expansão da atividade especulativa e a introdução de novos riscos. Por isso, Farhi e Cintra (2000) argumentam que os benefícios estabilizadores dos mercados de derivativos são contrabalanceados pelo fato de que seus mecanismos os tornam objetos de especulação, por conta do seu elevado poder de alavancagem. Neste mercado atuam, portanto, agentes hedgers, que procuram proteção; especuladores, que buscam ganhos por meio da variação de preços; e arbitradores, que compram e vendem em mercados diferentes devido a distorções de preços entre eles.

A análise do mercado de derivativos estende-se às negociações offshore, ou seja, aquelas de moeda doméstica de não residentes em jurisdição estrangeira. Estas, contudo, não existem isoladamente, já que se envolvem com operações vinculadas com o mercado onshore, o qual remete ao local das transações de moeda - de fato onde se forma a taxa de câmbio - sob as leis e regulamentações que vigoram no mercado doméstico. A influência do mercado offshore na formação da taxa de câmbio associa-se ao balanço de operações vendidas e compradas realizadas nele.

A importância do mercado de derivativos, em seu âmbito de contratos futuros, na determinação da trajetória cambial é destacada por Andrade e Prates (2012), que ressaltam o papel das expectativas neste contexto. Para os autores, o processo de compra e venda de divisas pelos bancos segue regras de negociação que incitam dois efeitos: o comportamento da demanda e a realização de lucros com a venda de ativos apreciados. Tais regras, por sua vez, são guiadas por dois tipos de expectativa sobre os movimentos futuros das taxas de câmbio: a) as de curto prazo, mais suscetíveis às informações recentes de conjuntura econômica; e b) as de médio prazo, que sofrem impacto dos fundamentos econômicos, tais como a situação do BP, o crescimento do Produto Interno Bruto (PIB), os diferenciais de juros e de inflação.

As especificidades do mercado de câmbio brasileiro são expressas, portanto, pelo conjunto de normas e instituições que atuam sobre os seus diversos segmentos, o que traz consigo seu comportamento microestrutural. Estas especificidades remetem-se à assimetria de liquidez entre os mercados à vista e futuro, que leva à diferença regulatória entre eles, com o mercado de derivativos escapando da rígida regulamentação imposta ao à vista. Dessa forma, a eficácia dos instrumentos de política cambial depende do conjunto de operações no mercado, dadas suas especificidades. 


\section{Banco Central do Brasil e a política cambial}

Em âmbito geral, Arestis et alii (2015) argumentam que as operações da autoridade cambial ocorrem para perseguir os seguintes objetivos: o equilíbrio das contas externas, a concessão de autonomia à taxa de juros da política monetária em relação à política cambial e a redução da volatilidade da taxa de câmbio. Logo, a política cambial é um determinante da taxa de câmbio. Ela define as regras, metas e objetivos desejados pela autoridade cambial com a operacionalização do regime cambial.

No Brasil, a autoridade cambial é o Banco Central do Brasil (Bacen) e suas ações ocorrem nos diversos segmentos do mercado cambial, tornando-o um relevante ator no mercado, uma vez que suas compra e venda de moeda estrangeira o permitem influenciar os níveis de liquidez, impactando a formação do câmbio. É competência do Bacen regular, fiscalizar e realizar intervenções discricionárias por meio de leilões junto a bancos selecionados a atuarem no mercado interbancário de câmbio. Estas intervenções ocorrem constantemente e buscam tanto amenizar a variação cambial quanto controlá-la, se a intenção da autoridade for buscar mudar o patamar do câmbio. ${ }^{9}$

Em termos práticos, as intervenções do Bacen no mercado de câmbio impactam sobre a posição que os bancos assumem em moeda estrangeira. Quando há intervenção no mercado de câmbio, a variação da posição cambial dos bancos é uma resultante de suas transações no mercado primário e das operações de compra e venda do Bacen. Souza e Hoff (2006, p. 22) formalizam essas operações na seguinte equação,

$$
A P-A R B C=\triangle P C B
$$

em que AP representam aquisições em dólares pelos bancos no mercado primário; $A R B C$ aquisições de reservas no mercado interno pelo Bacen e $\triangle \mathrm{PCB}$ corresponde à variação da posição comprada dos bancos. Esta equação mostra que a posição dos bancos não é independente das decisões tomadas por vários agentes, entre eles o Bacen.

9 Ressalte-se que o papel do Bacen se estende pelas regulamentações que ele elabora, por meio das quais autoriza e organiza os participantes do mercado bem como define quais operações são permitidas, o que lhe permite uma via indireta de influenciar as negociações em moeda estrangeira. 
Além das operações de compra e venda à vista do Bacen, as intervenções ocorrem também no mercado interbancário e futuro. De acordo com Rossi (2012), o Bacen pode causar, ao negociar no mercado interbancário, movimentos à vista da taxa de câmbio ao comprar ou vender dólares. Isto é, a autoridade monetária pode assumir uma ponta da negociação de moeda estrangeira e, com isso, variar a remuneração (conhecida como cupom cambial ${ }^{10}$ ) de contratos de dólares investidos no Brasil.

Por exemplo, o Bacen pode influenciar a depreciação à vista da taxa de câmbio com a compra de dólares, forçando o aumento do cupom cambial por conta da desvalorização da taxa de câmbio. Neste caso, se os bancos se deparam com o Bacen tentando reduzir a liquidez no mercado primário e, como visto, elevando o cupom cambial, eles podem ser estimulados a captar recursos via operações de linha ${ }^{11} \mathrm{e}$ os vendam ao Bacen. Nesse caso, o banco ganhará o diferencial entre as taxas de juros externa e interna além da taxa do cupom cambial.

Essa dinâmica de arbitragem dos bancos em suas posições com moeda estrangeira pode desencadear diferentes efeitos que, como sintetizado na equação 3 , dependerão da reação do Bacen. Uma das principais reações do Bacen são os leilões de swaps a termo, realizado por entrega física de dólares, objetivando conter a variabilidade da liquidez no mercado cambial (ROSSI, 2012). O swap é um instrumento derivativo cujo prêmio dá-se pela troca de rentabilidade entre ativos. A compra e a venda desses contratos ocorrem por meio de leilões em que os bancos participam ${ }^{12}$. Por sua vez, os swaps reversos são as operações de venda de swaps cambiais, enquanto que os de compra são os swaps "tradicionais". Sumariamente, os swaps reversos correspondem à uma posição ativa, remunerada pela variação cambial somada ao cupom cambial e uma posição passiva pagadora da taxa Selic. O swap cambial tradicio-

10 Para maior esclarecimento, o swap cambial é uma operação negociada pelo Bacen que dispõe da troca de um contrato cuja remuneração é dada pelo cupom cambial, que por sua vez corresponde à variação cambial e uma taxa de juros relativa à moeda estrangeira, embora tal remuneração seja em moeda doméstica.

11 Segundo Rossi (2015), as operações de linha são canais de financiamento em dólar entre bancos nacionais e estrangeiros que não envolvem a conversão entre reais e dólares e são as únicas operações de câmbio que não exigem contrato de câmbio, por isso não constam no fluxo cambial. Assim, os recursos que circulam nestas operações só alteram a posição de câmbio dos bancos quando são vendidos no mercado primário ou para o Bacen, convertendo-se a reais.

12 Segundo Bacen (2016) o swap tem valor final de US\$50.000,00 e valor inicial igual ao valor final com desconto da taxa de juro representada pelo cupom cambial. 
nal reflete uma posição ativa na taxa Selic e uma passiva em variação e cupom cambiais.

Por um lado, o Bacen pode comprar um montante equivalente ao fluxo de câmbio no mercado (fluxo cambial), o que tende a não afetar o cupom cambial ao não alterar a liquidez no mercado à vista - uma espécie de "zeragem" do mercado. Por outro lado, se a compra do Bacen supera ou é inferior ao fluxo, altera-se a liquidez e, portanto, o cupom cambial. Neste contexto, a política cambial exerce a administração do fluxo de divisas, visando a equilibrar excessos ou esgotamentos. Por exemplo, de acordo com Rossi (2012), o efeito de um fluxo cambial positivo sobre a taxa de câmbio pode ser neutralizado via compra de reservas cambiais pelo Bacen, como também por meio de regulação de fluxos de capitais entrantes ${ }^{13}$.

Se as intervenções forem voltadas para a redução da volatilidade cambial, isso pode ser favorável à especulação, porque operações carry trade podem surgir da estabilidade cambial, o que é ampliado pela manutenção de taxa de juros elevada relativamente às taxas internacionais. Neste cenário, a estabilidade fornece melhor previsibilidade e, assim, facilita a prospecção de ganhos dos agentes. $O$ diferencial de juros determinará os ganhos nestas operações, incentivando ou não o investimento e, com ele, a apreciação da taxa de câmbio (ROSSI, 2012).

Por fim, cabe salientar que a política cambial tem várias interfaces com as políticas monetária e fiscal e neste particular, Arestis et alii (2015) oferecem exemplos. Do ponto de vista da coordenação entre as políticas monetária e cambial, quando a primeira mantém a taxa de juros estável, ela auxilia a segunda a controlar a volatilidade nos fluxos de capitais. Por sua vez, a política cambial também transmite efeitos à política monetária. Medidas macroprudenciais cambiais tanto podem reduzir a volatilidade dos fluxos de capitais, diminuindo a pressão sobre a taxa de juros, quanto podem contribuir para um sistema financeiro saudável. Além disso, uma política cambial que mantém uma taxa de câmbio estável, arrefece o efeito pass through do câmbio para os preços domésticos, dando maior autonomia à taxa de juros da política monetária para lidar com questões domésticas. Se a política fiscal não precisa se financiar mediante dívida externa, as pressões sobre as reservas internacionais se reduzem, o que facilita a gestão

13 As aquisições de reservas podem criar custos; já os instrumentos de regulação não incorrem em custo fiscal e podem até mesmo elevar as receitas, como no caso da aplicação de imposto sobre operações financeiras sobre fluxos de capital internacional (IOF). 
da taxa de câmbio. Havendo dívida externa, se a política cambial é apta a manter a taxa de câmbio sem grandes oscilações, a gestão do orçamento público torna-se mais previsível, pelos menores impactos de ajustes patrimoniais sobre o estoque do passivo público e seus respectivos fluxos de pagamentos financeiros.

Em resumo, avalia-se uma multiplicidade de vias que definem a relação entre a formação da taxa de câmbio e a política cambial, cuja eficiência relaciona-se com as demais políticas, como também depende da atuação dos diversos agentes e instituições nos segmentos do mercado de câmbio. O comportamento instável da taxa de câmbio e dos fluxos de capitais é um desafio para a elaboração e implementação de políticas cambiais e, portanto, cabe analisar se os swaps exerceram influência sobre a dinâmica cambial ao longo do tempo.

\section{Análise empírica do comportamento da taxa de câmbio na presença dos swaps}

Para empreender a análise empírica sobre o comportamento da taxa de câmbio na presença de operações swaps, usam-se dois métodos econométricos. Por um lado, são utilizados modelos Auto-Regressive Conditional Heteroscedastic (ARCH) e Generalized Auto-Regressive Conditional Heteroscedastic (GARCH), para se averiguar a volatilidade condicional da taxa de câmbio nominal no Brasil no período entre julho de 2002 a setembro de 2015. A hipótese a ser testada é a de que este preço tem um comportamento instável em curtos intervalos de tempo. Dentre as finalidades para sua utilização, os modelos ARIMA, bem como os modelos de regressão linear aplicados a séries de tempo, procuram descrever, explicar e também prever o comportamento do nível, ou seja, da média condicional da variável dependente. Em muitas situações, entretanto, também é preciso conhecer o comportamento da variância condicional da série e obter previsões para ela. Esse procedimento é comum em variáveis financeiras, pois a série em estudo muitas vezes pode ser explicada pelo seu grau de volatilidade.

Em seguida, usam-se modelos de Vetores Autorregressivos (VAR) para se verificarem se os swaps são estatisticamente significantes para explicar a variância do comportamento da taxa de câmbio no Brasil. A regressão 
VAR é uma extensão de um modelo univariado autorregressivo para séries temporais multivariadas. A utilização desse procedimento remete-se ao intuito de descrever o comportamento dinâmico das séries econômicas e financeiras e nos modelos de previsão. $\bigcirc$ modelo reúne variáveis que são inscritas apresentando uma mesma quantidade de lags como funções de erro não correlacionados serialmente em um sistema de equações lineares dinâmicas. Utilizar essa estimação permite estabelecer, endogenamente, o relacionamento de variáveis comuns à literatura de condicionantes de variabilidade do câmbio e os swaps. ${ }^{14}$

Analisar-se-á o comportamento das taxas de câmbio real efetiva (TCRE $)^{15}$ e nominal (TCN), ambas calculadas relacionando o Real e o Dólar. A TCN pode ser compreendida como um ponto de partida resultante do desempenho da balança comercial, dos fluxos financeiros e do conjunto de reservas cambiais disponíveis em um país. Porém, variações nos preços domésticos e externos também afetam o primeiro e o último destes elementos, ao alterarem os preços relativos entre os países. Por esta razão, também se analisa empiricamente a TCRE, cujos dados obtêm-se no Ipeadata; os da TCN, decorrem do Banco Central do Brasil.

Os swaps (SWAP) cambiais são a proxy de intervenção da autoridade monetária para alterar a liquidez em moeda estrangeira no mercado de câmbio do país. No Brasil, a partir de abril de 2002, o Bacen começou a vender títulos juntamente com swaps de câmbio e, a partir de então, o passivo da dívida passou a ser contabilizado no balanço do Tesouro Nacional, enquanto o passivo cambial entrou na contabilidade do Bacen. Isso define o limite inferior do recorte temporal - julho de $2002-\mathrm{e}$ tais operações continuarem no quadro de medidas do Bacen explica o limite superior ser o mais recente em disponibilidade de dados vis-à-vis a composição deste trabalho - setembro de 2015. Para o estudo empírico, a série coletada dos swaps conta com colocações, resgates e estoque, importando à análise a diferença mensal entre colocações e resgates. Os dados de SWAP foram obtidos por meio dos relatórios de dívida pú-

14 Reitera-se que os modelos VAR permite, por meio da análise de decomposição da variância e função de impulso-resposta, testar um relacionamento endógeno apenas entre as variáveis selecionadas para o modelo empírico desenvolvido neste trabalho.

15 A cesta utilizada contém os seguintes países e seus respectivos pesos: China 24,6\%; EUA 15,5\%; Argentina 13,8\%; Países Baixos 8,2\%; Alemanha 6\%; Japão 5,3\%; Reino Unido $3,5 \%$; Itália 3,2\%; Chile 3,2\%; Rússia 2,9\%; Espanha 2,9\%; Coréia do Sul 2,8\%; França 2,8\%; Bélgica 2,7\%; México 2,6\%. 
blica mensal disponibilizados pela STN e deflacionados por meio do Índice Nacional de Preços ao Consumidor Amplo (IPCA), sendo a referência base dezembro de 2003.

Os preços relativos das mercadorias entre os países são outra variável considerada, o que justifica a análise do diferencial do nível de preços entre Brasil e Estados Unidos (DIFINF) como proxy para investigar o impacto do diferencial de preços sobre a taxa de câmbio que afeta, e é afetada pelo saldo comercial. Os dados utilizados são Índices de Preço ao Consumidor (IPC) americano e brasileiro, disponibilizados pelo International Financial Statistics.

A taxa de juros é uma importante variável em qualquer economia, devido à sua participação na alocação entre ativos financeiros ou produtivos. Em âmbito internacional, destaca-se, especialmente, a relação entre as taxas de juros domésticas e externas, guiando os fluxos financeiros internacionais. A escolha da análise deste trabalho reside na diferença entre as taxas de juros básicas brasileira e americana, vista como benchmark internacional (DIFJUROS). A fonte de dados da taxa de juros doméstica é o Ipeadata, enquanto que a americana é o Federal Reserve Data System.

O Risco-Brasil (RISCOBR) é um índice utilizado para expressar de forma objetiva o risco de crédito que investidores estrangeiros percebem no Brasil. Para essa variável, utiliza-se o EMBI+, índice que mede o retorno das dívidas externas de mercados emergentes mais ativamente negociadas. O cálculo envolve a diferença entre os rendimentos do título de um país e o de um título do Tesouro Americano, de prazo equivalente. Uma queda persistente no risco-país significa melhor percepção de risco, permitindo ao país mais acesso e melhores condições de prazo a capitais externos. Já o aumento persistente no risco piora as condições de acesso ao financiamento externo e pressiona a taxa de câmbio. Os dados de RISCOBR foram obtidos no Ipeadata.

Ademais, as expectativas sobre o comportamento futuro da taxa de câmbio influenciam o nível presente dela. Diversas negociações no mercado de câmbio balizam-se nas taxas de câmbios futuras, principalmente no mercado de derivativos, explicando parcela importante dos movimentos de capitais no curto-prazo. A expectativa de câmbio (EXPC) é obtida nos relatórios Focus do Bacen, indicando a taxa de câmbio que o mercado espera para diferentes momentos do tempo. 


\subsection{Os testes de volatilidade}

Em termos de uma análise de estatística descritiva prévia, apontam-se evidências de volatilidade nas TCN e TCRE, haja vista que os seus desvios-padrão representam, respectivamente, aproximadamente $22,5 \%$ e $24,5 \%$ dos valores médios. Outro sinal de volatilidade são os valores mínimos da TCN e da EXPC se encontrarem em junho e julho de 2011 e seus valores máximos em setembro de 2015, o que mostra que nos cinco últimos anos estão os mínimos e máximos da TCN e EXPC de todo o período 20022015. Entre 2002 e 2003, provavelmente devido à inflexão de um cenário desfavorável internacionalmente para uma melhor conjuntura mundial, o Brasil apresentou diferenciais de inflação e juros elevados, bem como a TCRE mais desvalorizada do período. Ademais, também em 2002, os swaps inseriram-se como instrumento de ajuste externo. Embora o valor máximo dos swaps tenha sido no começo da década de 2000, suas operações foram mais volumosas no pós-crise de 2008, notadamente entre 2013 e 2015, atingindo máximo em setembro de 2015 ( $\$$ \$ 406,63 bilhões).

Considerando que o período em análise deteve substantivas, bem como simples, variações da taxa de câmbio, sugere-se que haja heteroscedasticidade condicional, para cujo teste, nestas condições, envolve modelos ARCH (Engel, 1982) e GARCH (Bollerslev, 1986), para os quais se ajustam as séries de câmbio para se removerem as condições de não-estacionariedade, tendências de longo-prazo e quebras. Para o modelo da TCRE, a variação mensal do logaritmo das taxas de câmbio é a variável dependente. A sua defasagem de um período é uma variável explicativa, pois pelo correlograma dos resíduos aferiu-se que o modelo é autorregressivo de ordem 1 - AR (1). Para o modelo da TCN, a ordem é 2 e 7 , fazendo de suas segunda e sétima defasagens uma variável explicativa. Estimando-se o modelo ARCH (1) e GARCH $(1,1)$ para TCN, resulta-se na escolha do ARCH (1) por expressão da significância a $5 \%$, enquanto que o GARCH não foi estatisticamente significativo. Por sua vez, a TCRE foi estimada por ARCH (1) e GARCH (1, 1), culminando na escolha de estatística mais significativa o modelo ARCH (1). Em relação à normalidade, o teste Jarque-Bera impõe rejeição para ambas, TCRE e TCN.

Os Gráficos 1 e 2 representam a volatilidade de TCN e TCRE obtida via ARCH/GARCH. Percebe-se nos Gráficos elevada variabilidade cambial em todo o período, com exceções de curta duração. Os picos de variabilidade da TCN ocorrem no início de 2006, fins de 2008, em 2011 e 2015, em- 
bora oscilações de grande amplitude mostrem-se constantes durante todo o período. No que diz respeito à TCRE, as maiores variações são em 2002 e no final de 2008, porém também se revela constante a variabilidade da taxa de câmbio durante todo o período. Não obstante, houve momentos de volatilidade mais suave, de 2006 a 2008 e de 2013 a setembro de 2015 .

\section{Gráfico 1 Proxy de volatilidade da TCN}

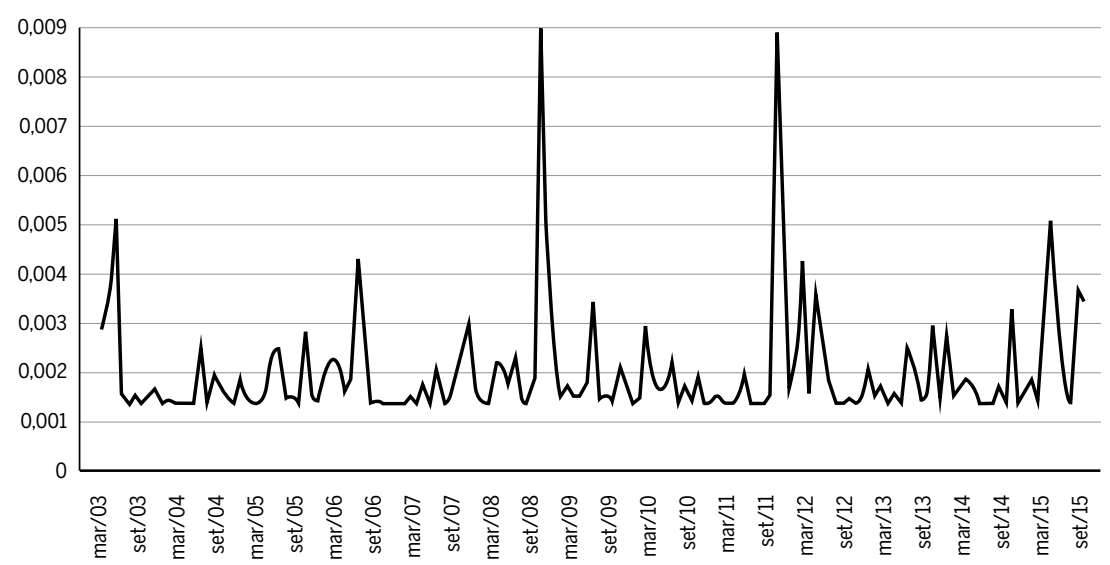

Fonte: Elaboração própria a partir de saídas do EViews 7.

\section{Gráfico 2 Proxy de volatilidade da TCRE}

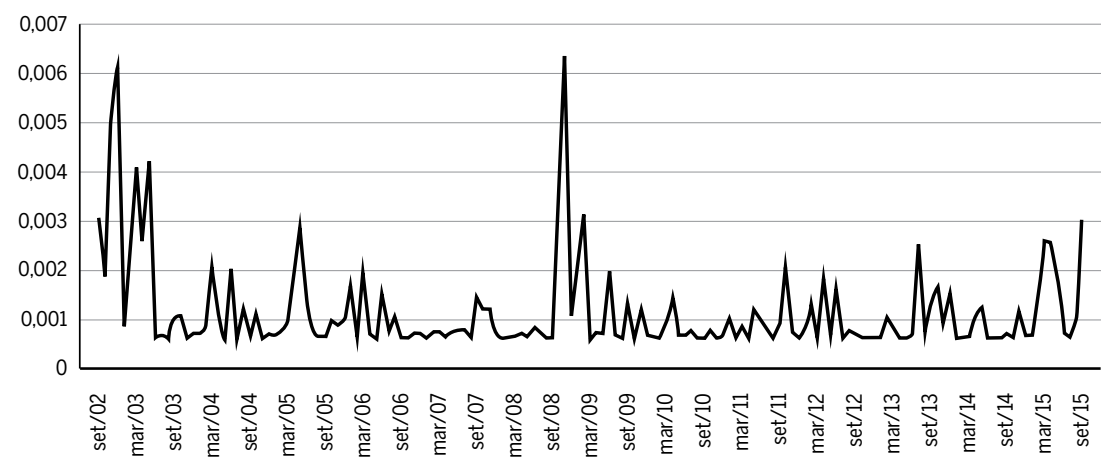

Fonte: Elaboração própria a partir de saídas do EViews 7.

A trajetória da diferença entre colocações e resgates de swaps nas operações do Bacen, encontra-se no Gráfico 3. Se comparado aos Gráficos 1 e 2, que apresentam a volatilidade para a taxa de câmbio no Brasil, o Gráfico 3 
mostra que a maior incidência de swaps ocorreu quando os modelos mostraram mais volatilidade. Destacam-se três períodos de maior operação com swaps, coincidentes com movimentos de grande magnitude das taxas de câmbio: 2002-2007; 2008-2009; e 2011-2015.

Gráfico 3 Colocações menos resgates de swaps (julho de 2002 a setembro de 2015) em $\mathrm{R} \$$ bilhões

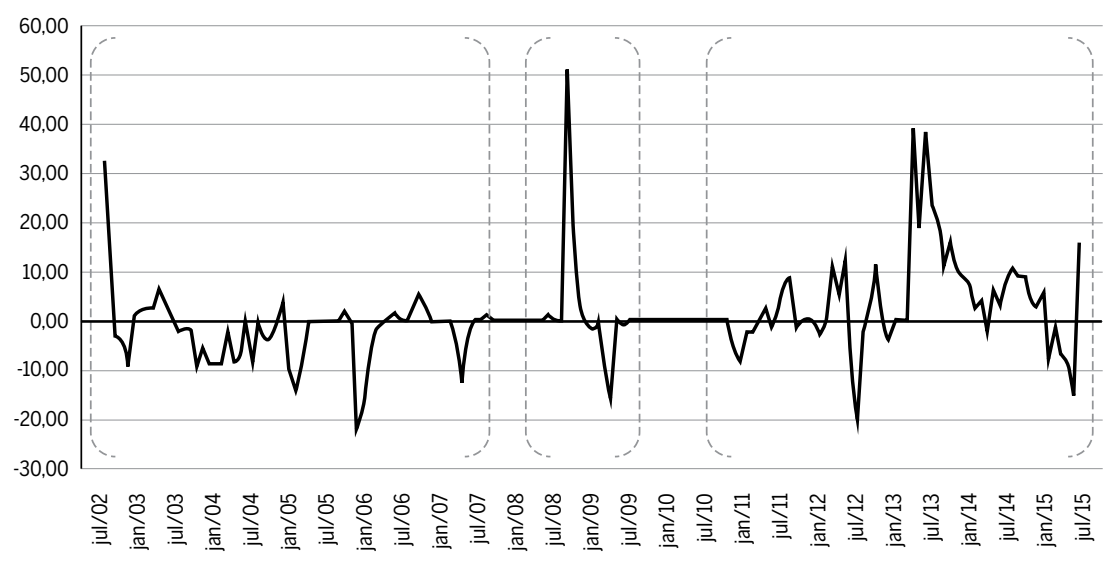

Fonte: Elaboração própria a partir de dados obtidos na Secretaria do Tesouro Nacional.

A variabilidade indicada pelos Gráficos 1 e 2 nos primeiros momentos desse período se deve ao ciclo político, por conta das eleições presidenciais em 2002. Neste período, a utilização dos swaps foi quase absolutamente restrita aos swaps reversos, os quais buscaram conter picos de desvalorização. De 2003 a 2007, há um quadro de expansão da economia mundial, com elevações nos preços das commodities, o que possibilitou um cenário de liquidez favorável à demanda externa, inclusive, com geração de superávit corrente, por conta dos saldos comerciais superavitários. Resultaram-se em pressão de valorização da taxa de câmbio e em maiores vendas de swaps do que compras em 2005 e 2006.

A crise financeira internacional de 2008-2009 cessou a trajetória anterior de liquidez. Este ponto de inflexão da trajetória cambial revela súbitas variações na taxa de câmbio decorrentes da redução do comércio internacional e de influxos de capitais. Devido à elevada desvalorização cambial neste momento, os swaps são mais utilizados, mesmo ocorrendo de forma não anunciada até então - o que pode significar uma possível menor eficá- 
cia sobre a volatilidade do período. Porém, há um intervalo neste período recente em que as operações swaps são interrompidas, de agosto de 2009 a janeiro de 2011, concomitante à redução da magnitude da volatilidade da TCN no período, como reporta o Gráfico 3.

Em 2011 reiniciam-se as operações swaps, como resposta à taxa de câmbio apresentar sinais de volatilidade e o início de uma trajetória de desvalorização, decorrente da permanência da crise internacional, que criou um cenário de liquidez desfavorável. A atuação via swaps, neste cenário, buscava produzir compensações à súbita perda de liquidez nos mercados de câmbio. Não obstante, as operações swaps se tornaram mais recorrentes, além de passarem a ser anunciadas, a partir de agosto de 2013. Em 2014, o Bacen anunciou extensão do programa para todo o ano. Em 2013-2015, o comportamento de volatilidade apresentado pela TCRE é mais suave e coincidente com o aumento de operações anunciadas de swaps, que atingiu um estoque de $\mathrm{R} \$ 406,63$ bilhões em setembro de 2015, bastante superior à média do período, $\mathrm{R} \$ 49,17$ bilhões - um dos maiores programas de intervenção entre as economias emergentes.

Os swaps são intervenções que ocorrem no mercado cambial, via venda de reservas internacionais, ou, mais utilizado recentemente, usando instrumentos de derivativos liquidados com troca de indexadores (juros por câmbio, por exemplo) ou em outras moedas - o Bacen também liquida em Real para vender Dólares. A eficácia do swap cambial depende da crença dos agentes em poder trocar Reais por Dólares ao adquirir swaps. Nesta sistemática, insere-se o risco de convertibilidade como mais uma referência para a aquisição dos ativos por parte dos agentes. Isto é, se há confiança de que eles podem entregar e receber moeda estrangeira sem grandes impedimentos, a disposição a trocar sua demanda por Dólares ou Reais se eleva.

Os incentivos e justificativas que fazem o Bacen utilizar operações swaps podem ser numerosos, no entanto é possível realçar seus principais. Os swaps podem ser vistos como contratos de para troca de riscos, incentivar investimentos e criar segurança contra o risco para agentes, o que the fornece um papel importante na formação de expectativas. Outra justificativa à utilização dos swaps é um desdobramento deste: a influência sobre o comportamento da moeda estrangeira que os contratos swap exercem pode culminar numa alteração de liquidez no mercado de câmbio e, assim, a autoridade monetária auferiria controle indireto no mercado primário e no mercado de derivativos, dada sua função de hedge - e direto no mer- 
cado secundário, permitindo-a um domínio maior do que antes sobres os fluxos cambiais nestes segmentos e, consequentemente, na formação da taxa de câmbio.

Para uma análise mais acurada do câmbio face às operações swap, examina-se a relação delas com o PEL. $O$ ativo externo é, em grande parte, denominado em moedas estrangeiras, enquanto que, dos itens que compõe o passivo, estão em Real uma parte do investimento estrangeiro direto referente à participação de capital, o investimento em ações negociadas no Brasil por estrangeiros, e os títulos de renda fixa negociados no País. As demais operações no passivo externo brasileiro são denominadas em outras moedas. Dessa forma, considera-se a composição cambial do passivo externo brasileiro, incluindo nos cálculos as operações com derivativos cambiais, tais quais os contratos futuros de Dólar, os contratos de swaps e opções de Dólar realizadas pelos investidores ao buscarem hedge cambial.

A primeira constatação é que o ativo externo brasileiro não sofre grande oscilações e segue uma trajetória crescente, expandindo-se de US\$150 bilhões a US\$ 700 bilhões no período em análise. O passivo externo brasileiro, por sua vez, também mostra tendência de crescimento, embora tenha oscilações em 2008 com variabilidade que não se encerra depois de então, como mostra o Gráfico 4. Como se pode ver no Gráfico, seguindo as tendências do passivo e ativo separadamente, o PEL é crescente sem apresentar movimentos súbitos de 2002 a 2007. O PEL assume valor mínimo em 2002 e máximo em 2011, coincidindo com o valor máximo do passivo, embora valores de mesma magnitude reincidiram em 2012, 2013 e 2014.

De junho de 2008 a junho de 2009, o PEL assumiu valores menores que o ativo externo, por conta da expressiva queda na liquidez internacional, o que implicou redução do passivo externo, como mostra o Gráfico 4. Contudo, já em meados de 2009 a situação se altera, com oscilação na liquidez internacional, causada pela expansão monetária realizada pelos países desenvolvidos, como os Estados Unidos da América, o Reino Unido e o Banco Central Europeu. A combinação entre ciclos voláteis de liquidez disponível e risco acentuado decorrente da crise global, promoveu uma persistente volatilidade do passivo externo a partir de junho de 2011 até junho de 2015. Neste cenário, as operações swaps são realizadas para protegerem os detentores de dívida em moeda estrangeira contra movimentações no valor decorrentes de oscilações na taxa de câmbio. Uma ausência deste tipo de proteção incorreria em um investimento de maior risco aos agentes proveniente da varia- 
bilidade do câmbio, tendo em vista que dívidas compromissadas em moeda estrangeira possuem magnitude sensível à variação da taxa de câmbio. Isto pode implicar uma aversão a investimentos arriscados, alterar a composição de ativos na economia e, inclusive, afetar a contabilidade do BP.

\section{Gráfico 4 Passivo externo líquido (julho de 2002 a junho de 2015) - em US\$ bilhões}

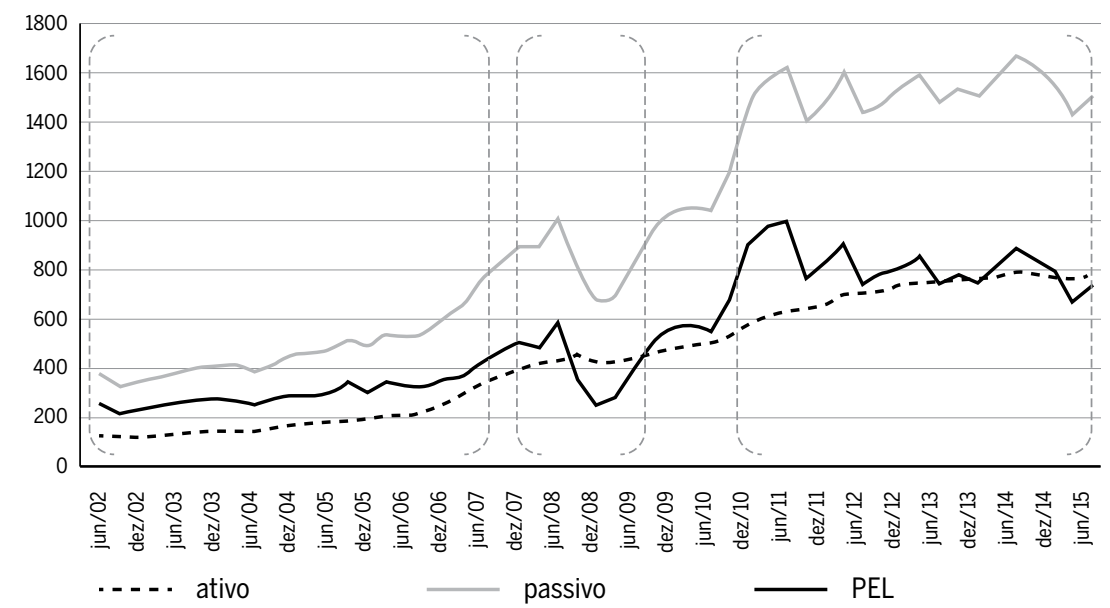

Fonte: Elaboração própria a partir de dados obtidos no Bacen.

\subsection{Os testes com vetores autorregressivos}

A decomposição da variância (ADV) é uma das maneiras de se analisarem os resultados do modelo VAR ${ }^{16}$. Pois bem, a ADV para TCN reflete uma explicação pelas demais variáveis em conjunto em menos de $4 \%$, sendo o Risco-Brasil sozinho responsável por $2,4 \%$. A proxy de risco é ainda explicativa de $6,32 \%$ das oscilações dos swaps, o que mostra como ele funciona

16 Dado o limite de espaço, os procedimentos preliminares à estimação são comentados nesta nota. Em ambos os modelos VAR não há estacionariedade (com análise baseada nos quatro critérios tradicionais) das séries em nível, à exceção do SWAP. As séries não estacionárias foram transformadas em logaritmo neperiano e, então, fez-se a primeira diferença para elas; já para a série DIFINF, que apresentou valores negativos, foi necessário remover a estacionariedade por meio de seu valor relativo. A escolha de lags foi, para ambos, duas defasagens (novamente, com base nos quatro critérios) e os modelos seguem uma ordem estabelecida de acordo com o critério de causalidade de Granger, apresentada na disposição das variáveis da esquerda para a direita nas Tabelas 1 e 2 . Por fim, como mostra o teste $A R$ Roots, ambos os modelos também são estáveis. 
como um mecanismo de hedge quando se percebem movimentações na sensação de risco. Por um lado, os swaps explicam 0,1\% dela e 2,724\% da variância da expectativa do câmbio. Por outro lado, os swaps têm sua variância explicada em $14,6 \%$ pela TCN, a maior magnitude porcentual de explicação, enquanto que a expectativa de câmbio pouco explica a variância dos swaps, 0,89\%. Embora a TCN apresente baixa resposta à variância dos swaps, estes são sensíveis à variância daquela. A expectativa cambial é bastante relacionada à TCN, uma vez que os agentes assumem contratos com resultados esperados baseados nas informações de preços do presente e de acordo com as variações recentes deles. Logo, a relação entre câmbio à vista e futuro é importante condicionante para a determinação da TCN. Os indicadores de risco são outra fonte de referência para formação de expectativa sobre o câmbio futuro, representando mais de $3 \%$ de sua variância. Nominalmente, a variância TCN é pouco explicada pela inflação.

Baseando-se na perspectiva pós-keynesiana, a diferença entre o câmbio presente e futuro significa ganhos para alguns agentes e perdas para outros. Neste contexto e diante dos resultados alcançados, assume-se a seguinte ordem de influência dos swaps sobre a variância da TCN: os swaps impactam sobre as expectativas acerca do câmbio futuro, o que contribui para formar a TCN, ou seja, o câmbio à vista. Logo, o Bacen, ao realizar intervenções swaps, observa as taxas esperadas de câmbio, eis a importância do componente expectacional, porém para afetar o comportamento da taxa corrente.

Tabela 1 ADV para o modelo VAR da TCN*

\begin{tabular}{l|rrrr|r|r|r}
\hline \multirow{2}{*}{ Dependente } & \multicolumn{1}{|c}{} & \multicolumn{2}{c}{} & \multicolumn{2}{|c}{ Explicativas } \\
\cline { 2 - 8 } & $\begin{array}{r}\text { TCN } \\
\text { _DL }\end{array}$ & $\begin{array}{r}\text { RISCOBR } \\
\text { _DL }\end{array}$ & $\begin{array}{r}\text { DIFJUROS } \\
\text { _DL }\end{array}$ & $\begin{array}{r}\text { SWAP } \\
\text { _IPCA }\end{array}$ & $\begin{array}{r}\text { DIFINF } \\
\text { _RL }\end{array}$ & $\begin{array}{r}\text { EXPC } \\
\text { DL }\end{array}$ \\
\hline TCN_DL & 96.69 & 2.42 & 0.36 & $\mathbf{0 . 1 1}$ & 0.31 & 0.11 \\
\hline RISCOBR_DL & 39.40 & 57.43 & 1.32 & 0.12 & 1.64 & 0.09 \\
\hline DIFJUROS_DL & 1.54 & 3.90 & 92.84 & 0.76 & 0.83 & 0.14 \\
\hline SWAP_IPCA & $\mathbf{1 4 . 6 0}$ & 6.32 & 1.21 & 76.19 & 0.79 & $\mathbf{0 . 8 9}$ \\
\hline DIFINF_RL & 22.68 & 0.20 & 6.86 & 0.98 & 67.81 & 1.47 \\
\hline EXPC_DL & 61.92 & 3.19 & 0.74 & 2.72 & 0.54 & 30.88 \\
\hline
\end{tabular}

* É comum a estabilidade dos valores ser atingida partir do período 10-12 da estimação do ADV, o que justifica os valores apresentados serem do período 12. Os realces são dos autores para acentuar a análise pretendida.

Fonte: Elaboração própria a partir de saídas do EViews 7. 
A Tabela 2, abaixo, reporta a ADV da TCRE. Em relação à TCN, a TCRE tem sua variância mais bem explicada, $82 \%$, pelas variáveis do modelo. Comparando-se a influência dos swaps, tem-se para a TCRE 4,02\% contra $0,1 \%$ da TCN. Estas diferenças podem ser explicadas pela própria metodologia de cálculo, uma vez que a TCRE pondera os principais parceiros do Brasil no comércio exterior, considerando-se os preços relativos domésticos e internacionais, enquanto a TCN não. Por isso a TCRE, mostra-se mais sensível ao diferencial de inflação, que impacta os fluxos comerciais e a taxa de câmbio (que entra no cálculo da TCRE). Em relação às semelhanças com a TCN, a variância do diferencial de juros explica de forma parecida a variância das TCN e TCRE.

Uma diferença importante nos modelos é o resultado do que movimenta os swaps: 0,54\% das variações na TCRE diante de 14,6\% explicados pela TCN. Intuitivamente, os swaps respondem mais à TCN do que à TCRE, todavia esta é mais sensível aos swaps do que aquela. Os swaps respondem à TCRE, com coeficiente próximo a $1 \%$, o que pode representar uma causalidade mútua baixa, tendo em vista que os swaps são utilizados pelo Bacen observando movimentos na própria taxa de câmbio e, portanto, seria de se esperar que variações conjuntas na TCRE e nos swaps detivessem valores mais elevados. Por seu turno, os swaps influenciam a taxa de câmbio esperada também em torno de $2 \%$.

Tabela 2 ADV para o modelo VAR da TCRE*

\begin{tabular}{l|r|r|r|r|r|r}
\hline Dependente & \multicolumn{1}{|c}{} & \multicolumn{1}{c}{} & \multicolumn{2}{|r}{ Explicativas } \\
\cline { 2 - 8 } & $\begin{array}{r}\text { RISCOBR } \\
\text { _DL }\end{array}$ & $\begin{array}{r}\text { DIFJUROS } \\
\text { _DL }\end{array}$ & $\begin{array}{r}\text { SWAP } \\
\text { IPCA }\end{array}$ & $\begin{array}{r}\text { TCRE } \\
\text { _DL }\end{array}$ & $\begin{array}{r}\text { DIFINF } \\
\text { RL }\end{array}$ & $\begin{array}{r}\text { EXPC } \\
\text { DL }\end{array}$ \\
\hline RISCOBR_DL & 96.62 & 1.30 & 0.09 & 0.20 & 1.73 & 0.06 \\
\hline DIFJUROS_DL & 5.13 & 92.18 & 0.69 & 1.02 & 0.72 & 0.26 \\
\hline SWAP_IPCA & 19.51 & 1.15 & 76.46 & $\mathbf{1 . 4 4}$ & 0.54 & $\mathbf{0 . 9 0}$ \\
\hline TCRE_DL & 30.96 & 0.88 & $\mathbf{4 . 0 2}$ & 63.57 & 0.18 & 0.39 \\
\hline DIFINF_RL & 12.81 & 6.59 & 0.85 & 4.76 & 72.53 & 2.47 \\
\hline EXPC_DL & 36.85 & 0.56 & $\mathbf{2 . 1 5}$ & 28.11 & 1.72 & 30.61 \\
\hline
\end{tabular}

*É comum a estabilidade dos valores ser atingida partir do período 10-12 da estimação do ADV, o que justifica os valores apresentados serem do período 12 . Os realces são dos autores para acentuar a análise pretendida.

Fonte: Elaboração própria a partir de saídas do EViews 7. 
Saliente-se que em ambos os testes, um resultado se destaca: os coeficientes da variância do risco-Brasil são explicativos; assim, o indicador de risco representa a variável com alto poder explicativo para a TCN, TCRE, expectativa de câmbio e os swaps. De acordo com a perspectiva pós-keynesiana, a expectativa dos agentes é um fator crucial para que ele estabeleça sua estratégia de formação de carteira, sejam com ativos denominados em moeda estrangeira seja em moeda doméstica. Assim, a variável risco-Brasil reflete meios pelos quais a estratégia de alocação de ativos consegue influenciar fluxos externos no País sendo, então, uma proxy relevante para evidenciar os riscos atrelados aos ativos brasileiros, que podem causar impacto significativo na necessidade de intervenções via swaps, sobretudo nas variações nas taxas esperada de câmbio e TCRE. A proxy expectacional via riscos, portanto, define o modo pelo qual a alocação dos ativos internacionais será realizada pelos agentes, e este impacto é percebido na ADV para a TCRE, em que não só as taxas de câmbio, atual e esperada, serão afetadas, como também respostas operacionais de swaps cambiais. Os resultados podem ser ilustrados pela Figura 2.

Figura 2 Sumário dos resultados dos testes ADV

\section{a) Taxa de câmbio nominal}

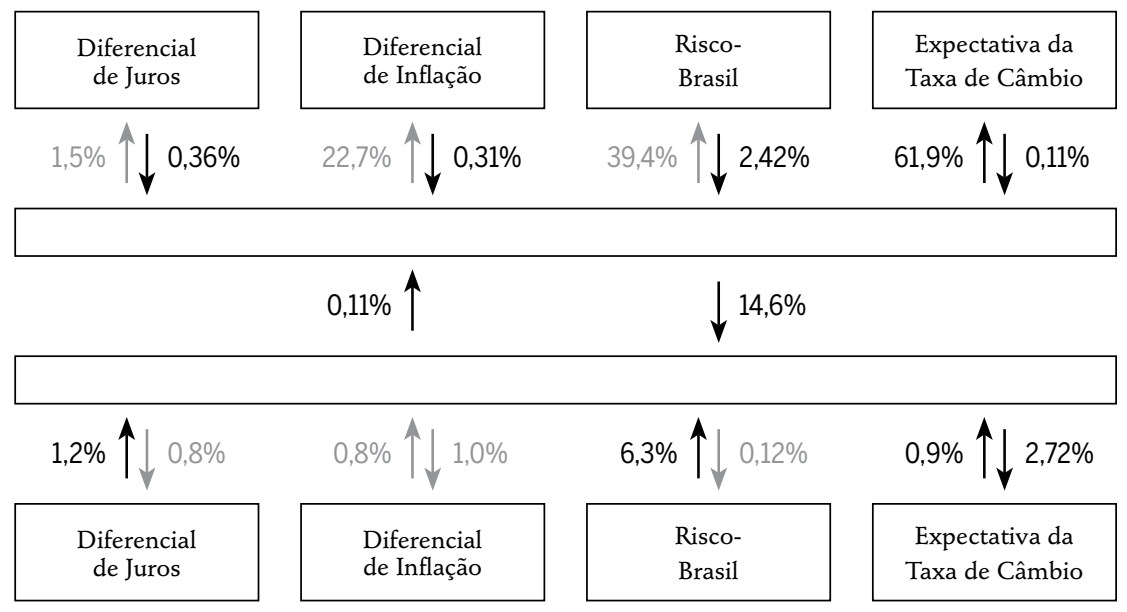




\section{b) Taxa de câmbio real efetiva}

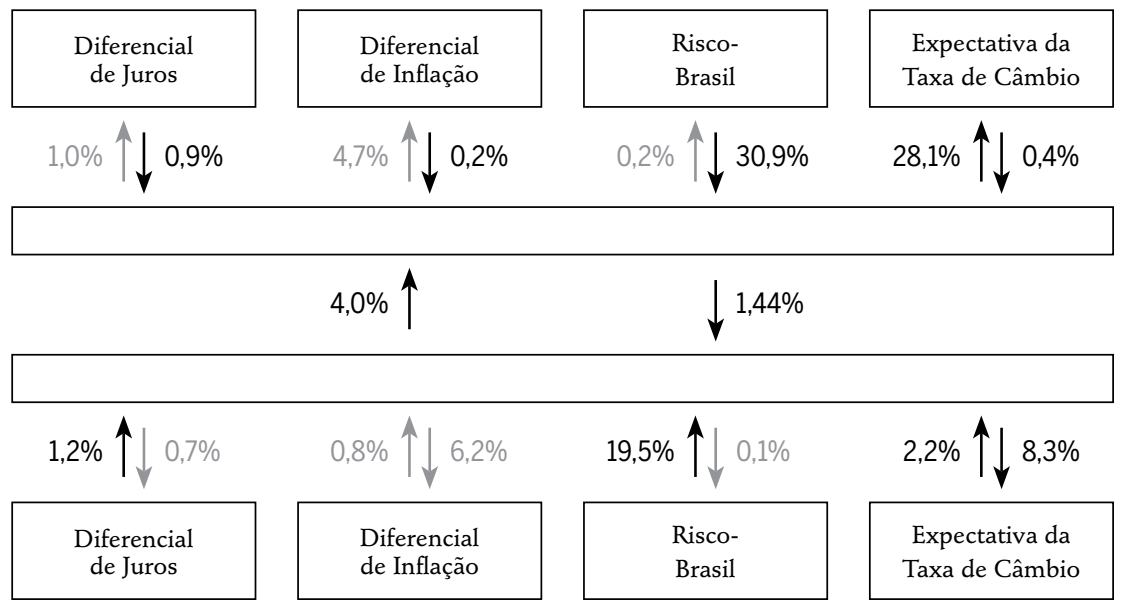

Fonte: Elaboração própria a partir de saídas do EViews 7.

A análise da Função Impulso-Resposta (FIR $)^{17}$, por sua vez, é o outro método de avaliação. No caso deste artigo, a análise foi construída com impulsos generalizados e respostas acumuladas. Os resultados são apresentados na Figura 2, abaixo, para a TCN, e na Gráfico 5, para a TCRE. Nelas são reportados apenas as respostas estatisticamente significantes dos testes econométricos; seria ocioso inserir resultados que não acrescessem estatisticamente à analise.

Como mostra a Gráfico 5, todos choques são diretos, isto é, as variáveis sob análise caminham na mesma direção, com a exceção na reação inicial da expectativa de câmbio aos swaps. Os swaps apresentam maior resposta às variações da TCN e esta responde pouco aos swaps e ligeiramente menos às expectativas do câmbio. Por sua vez, as expectativas respondem rápida e intensamente à TCN; os swaps respondem às expectativas, mas suavemente, da mesma forma que as expectativas também não respondem intensamente aos swaps. Assim, a discussão dos resultados indica que os swaps buscam, com efeito estatístico significativo, controlar a TCN presente para que as expectativas sobre o câmbio futuro se amenizem, evitando que con-

17 A FIR mostra como as variáveis endógenas reagem no tempo a um choque num só momento num dos termos de perturbação. Dado que as perturbações podem estar contemporaneamente correlacionadas, estas funções explicam de que forma uma variável reage a uma inovação em outra em vários períodos de tempo, considerando todo o resto constante. 
venções altistas - importante elemento conformador de expectativas para a teoria pós-keynesiana - sobre a TCN se formem, desestabilizando-a e conduzindo a eventuais efeitos manada. Embora com baixo impacto, ou seja, não sendo um determinante, os swaps têm influência sobre as expectativas e a TCN. Igualmente, estas variáveis se condicionam mutuamente, o que corrobora os mecanismos de transmissão da TCN para as expectativas e, então, dos swaps para a TCN e para as expectativas. Novamente, as expectativas, relevante variável para a teoria pós-keynesiana, faz-se relevante para se compreenderem as intervenções do Bacen com swaps cambiais.

\section{Gráfico 5 FIR para o modelo VAR da TCN}

Accumulated Response to Cholesky One S.D. Innovations
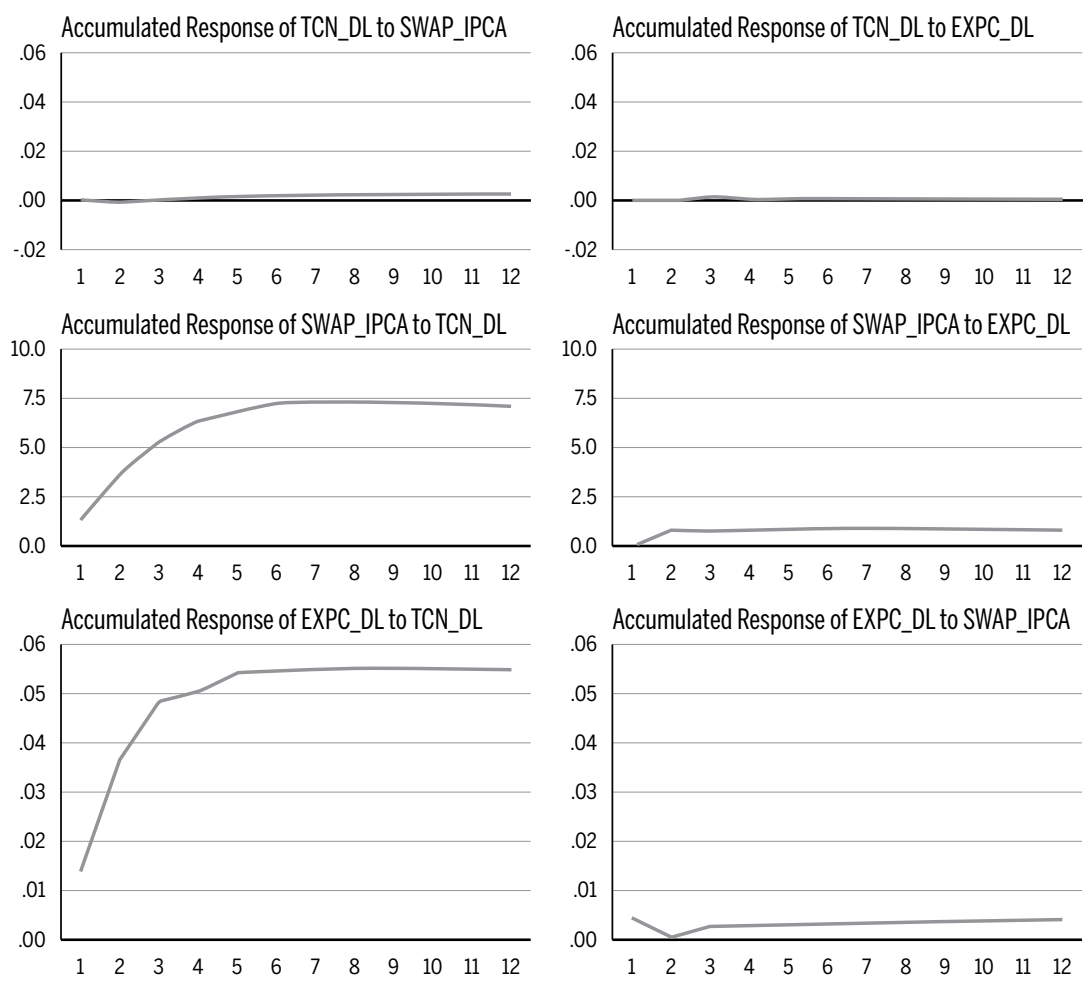

Fonte: Elaboração própria a partir de saídas do EViews 7.

Já a Gráfico 6 mostra que a maioria das relações entre as variáveis também apresentam reação direta - exceto as reações iniciais das expectativa de câmbio e TCRE aos swaps - com a diferença, em relação à TCN, de que 
os choques tendem a se dissipar no tempo. Tal qual a TCN, e provavelmente causada por mudanças nela, as expectativas respondem fortemente à TCRE; os swaps e as expectativas também, porém com menor valor. Igualmente com pequena sensibilidade, os swaps respondem às expectativas e estas a eles. Os swaps têm pouco impacto, e concentrado no curto prazo, sobre a TCRE, semelhante ao efeito dos swaps nas expectativas. Infere-se dos resultados que os mecanismos de transmissão do swap em muito se assemelham aos da TCN - talvez, ser ela parte da TCRE explique as similaridades percebidas nas duas taxas. $O$ principal efeito que se tem são as expectativas respondendo a mudanças na TCRE. Já modificações nas expectativas pouco refletem-se sobre o TCRE. Ao impactarem, ainda que modestamente, sobre a TCRE, os swaps também alcançam as expectativas e influenciam, assim, o movimento desta taxa. Com efeitos restritos, conclui-se que os swaps são condicionantes modestos da TCRE, tal qual também o foram da TCN, todavia com maior efeito estatístico.

\section{Gráfico 6 FIR para o modelo VAR da TCRE}

Accumulated Response to Cholesky One S.D. Innovations
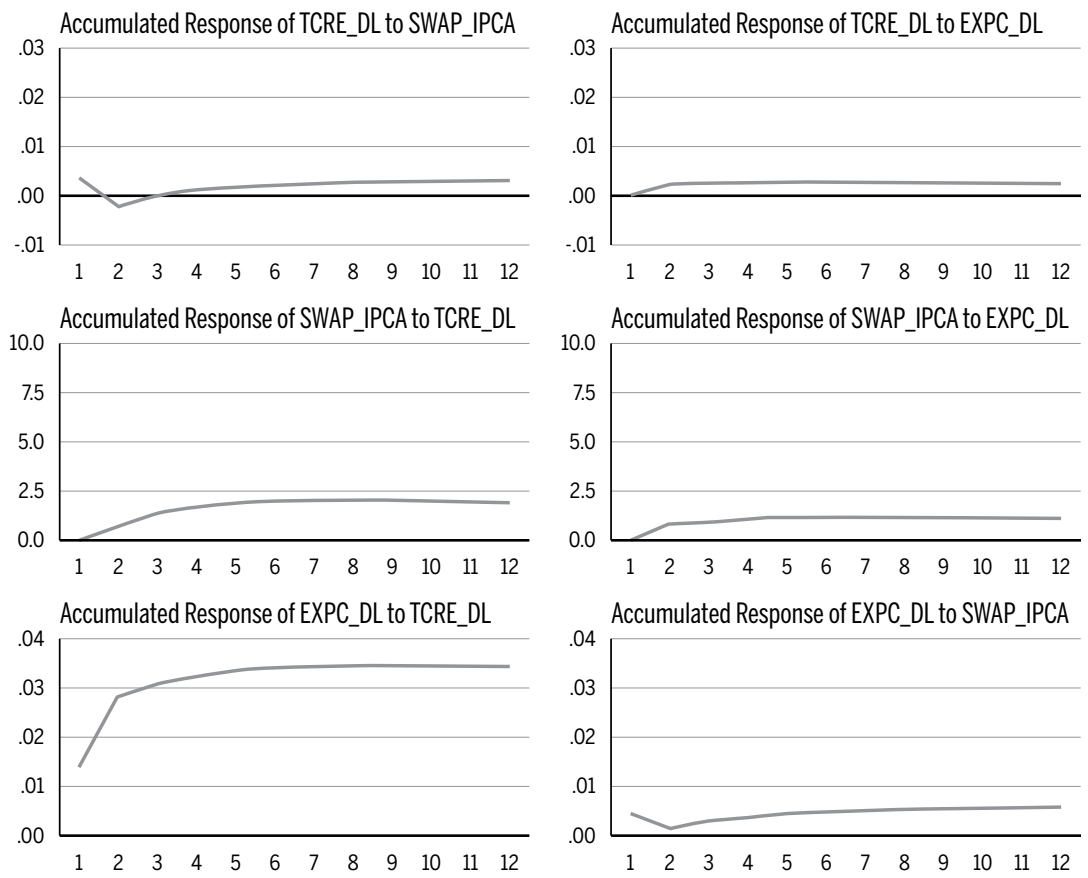

Fonte: Elaboração própria a partir de saídas do EViews 7. 


\section{Considerações finais}

Objetivou-se neste trabalho investigar a dinâmica cambial no Brasil ante os swaps do Bacen, buscando entender o papel deles como condicionantes daquela. Os swaps são uma intervenção do Bacen visando à contenção da volatilidade da taxa de câmbio, buscando condicionar a liquidez no mercado cambial e fornecer hedge para as operações denominadas em moeda estrangeira.

As análises ARCH/GARCH, de 2002 até setembro de 2015, revelam um comportamento volátil da TCN e da TCRE por todo período. Contudo, há momentos em que a volatilidade é súbita e elevada comparada à média do período analisado, concomitante acompanhada por um aumento nos leilões swaps praticados. Estes períodos foram: (i) 2002-2004, quando predominam os efeitos remanescentes da crise cambial de 2002, cujas repercussões causaram intenso uso de swaps; (ii) 2008-2009, em que os efeitos da crise financeira internacional ocasionaram refluxos de capitais com rápida e intensa desvalorização cambial; e, (iii) 2011-2015, quando a conjuntura mundial desfavorável se prolongou, com os países desenvolvidos realizando políticas monetárias pouco convencionais, implicando expectativas arredias dos investidores internacionais e, assim, volatilidade cambial.

Os testes VAR mostraram que, por um lado, os swaps apresentaram coeficiente significativo em reposta à TCN e baixo para a TCRE; por outro lado, os swaps apresentaram coeficientes de explicação baixos, embora não nulos, sobre as TCN e TCRE, o que indica uma fraca contenção da variabilidade cambial. Ou seja, o swap não é capaz de determinar a dinâmica da taxa de câmbio, mas a influência, sob o seguinte mecanismo de transmissão: variações nas TCN e TCRE implicam rápida e intensa reação nas expectativas e nas perspectivas de risco, que passam a incorporar a esperança de novos movimentos cambiais. Diante disso, os swaps, mesmo com magnitude menor do que a reação das expectativas, são vendidos pelo Bacen e condicionam, ainda que modestamente, a dinâmica da TCN e da TCR e as expectativas acerca de seus patamares futuros. Foram estes os resultados empíricos apresentados pelas ADV e FIR. O relativo baixo poder de explicação dos swaps entre 2002-2015 sobre a TCN e TCRE pode relacionar-se à forma pela qual eram operacionalizados, uma vez que seu montante era transacionado sem divulgação prévia, o que passou a ser feito desde agosto de 2013. Este argumento é corroborado pelo fato de as 
expectativas de taxa de câmbio futura serem influenciadas, embora sem elevada significância, pelas operações correntes de swaps.

Ainda pelo modelo VAR, conclui-se uma das características fundamentais de qualquer tipo de investimento, a relação risco-retorno envolvida em negociações entre moedas, causando impactos significativos do risco-Brasil sobre as taxas de câmbio analisadas - especialmente à TCRE - e aos swaps. Isto é, ao se pensar parte da determinação de ativos financeiros sobre a dinâmica cambial, um trade-off é intuitivamente compreendido: quanto maior a possibilidade de se obterem ganhos, maior tende a ser o risco envolvido e maior transmissão sobre os preços relativos da moeda e sobre os canais que buscam conter sua volatilidade. Respalda-se também, nesta análise, a posição que o Brasil se insere no SMFI, cujas características envolvem retornos elevados e riscos que também o são.

Embora fora dos modelos estimados, realça-se a importância da relação entre o PEL e os swaps, uma vez que ele reflete a constituição da posição de compromissos e investimentos externos dos agentes. A análise mostra ser comum, em momentos de adversidade internacional, o PEL assumir comportamento volátil, especialmente devido à instabilidade do passivo externo. Neste sentido, uma constante oscilação no passivo no período 2011-2015 é coincidente com a intensificação das operações swaps nestes anos, indicando, portanto, a oferta de hedge cambial por parte do Bacen aos agentes endividados em moeda estrangeira.

Por fim, a investigação empírica permite questionar - especialmente sob a atual conjuntura de problemas fiscais - a utilização maciça dos swaps, uma vez que estatisticamente as taxas de câmbio apresentam baixo sinal de resposta a eles. Isto é, os swaps acarretam custos ao Bacen que são, ao final do período contábil, fluxos de gastos financeiros da STN. Logo, eles podem implicar aumento de déficits públicos. Toda a vez que a variação cambial ao longo do período vigente do contrato do swap for superior à taxa de juros, o Bacen cobre essa diferença, e vice-versa. Em âmbito fiscal, portanto, estas operações envolvem custos fiscais significativos em relação ao pagamento de juros, sendo que seu efeito sobre as TCN e TCRE não são por demais relevantes - pelo menos diante dos resultados empíricos aqui alcançados. Talvez seja mais interessante ao Bacen realizar operações conjuntas de swaps com linhas de crédito de moeda estrangeira via uso de parte das reservas internacionais, o que pode ter mais impacto na administração da taxa de câmbio, sem colocar em risco o buffer que elas ofere- 
cem e sem resultarem em custos à política fiscal. Controle sobre capitais especulativos de curto prazo, como já bastante discutido na literatura pós-keynesiana, inclusive em várias das referências utilizadas neste artigo, são também relevantes e podem dar mais eficácia aos swaps.

\section{Referências}

ANDRADE, R. P; PRATES, D. M. Dinâmica da taxa de câmbio em uma economia periférica: uma abordagem keynesiana. Nova Economia, Belo Horizonte, 2012.

ARESTIS, P.; TERRA, F. H. B.; FERRARI FILHO, F. Post Keynesian macroeconomic policy regime. $19^{\text {th }}$ conference of the research network macroeconomics and macroeconomic policies. FMM Research Network. Macroeconomic Policy Institute. Outubro, 2015.

BOLLERSLEV, T. Generalized autoregressive conditional heteroskedasticity. Journal of Econometrics, 31, p. 307-327, 1986.

CONTI, B. M.; PRATES, D. M.; PLIHON, D. A hierarquia monetária e suas implicações para as taxas de câmbio e de juros e a política econômica dos países periféricos. Economia e Sociedade, Campinas, p. 341-372, 2014.

CYSNE, R. P. Passivo Externo Líquido Versus Dívida Externa Líquida. 2008. Disponível em: $<$ www.fgv.br/professor/rubens/HOMEPAGE/ARTIGOS_E_ REPORTAGENS_DE_POL_ ECON/Artigos_Publicados/2008/Passivo\%20Externo.pdf>. Acesso em: 12 dez. 2015.

ENGEL, R. F. Autoregressive conditional heteroscedasticity with estimates of the variance of the United Kingdom inflation. Econometrica, 1982.

FARHI, M; CINTRA, M. A. M. Convivendo com o Câmbio Flutuante. Revista de Economia Política, v. 20, n. 3, 2000.

GALA, P.; LIBÂNIO, G. Taxa de câmbio, poupança e produtividade: impactos de curto e longo prazo. Economia e Sociedade. Campinas, p. 229-242, 2011.

HARVEY, J. T. Exchange Rates of Trade Flows: A Post Keynesian Analysis. Journal of Post Keynesian Economics. v. 14, n. 1. 1991.

HARVEY, J. T. Teaching Post Keynesian Exchange Rate Theory. Texas Christian University. Department of Economics. Working Paper Series. Novembro, 2006.

HARVEY, J. T. Currency Market Participants' Mental Model and the Collapse of the Dollar, 2001 2008. Texas Christian University. Department of Economics. Working Paper Series. Fevereiro, 2009a.

HARVEY, J. T. Currencies, capital flows and crises: A post Keynesian analysis of Exchange rate determination. London: Routledge, 2009 b.

IPEADATA. Metodologia EMBI. Base de dados. 2015. Disponível em: < www.ipeadata.gov.br/ doc/metodologia\%20embi.doc>. Acesso em: 14 dez. 2015.

KEYNES, J. M. A teoria geral do emprego, do juro e da moeda. Os Economistas. São Paulo: Atlas, 1996. 
The 'Ex-Ante' Theory of the Rate of Interest. The Economic Journal, v. 47, n. 188, dec. 1937. Publicado por Blackwell Publishing for the Royal Economic Society, 2010. Disponível em: <http://www.jstor.org/stable/2225323. Acesso em: 08 jan. 2015.

PRATES, D. M. As assimetrias do sistema monetário e financeiro internacional. Revista de Economia Contemporânea. Rio de Janeiro. Maio-Agosto, 2005.

ROSSI, P. L. Taxa de câmbio no Brasil: Dinâmicas da arbitragem e da especulação. Universidade estadual de Campinas, Instituto de economia, Tese, 2012.

ROSSI, P. L. Política cambial no Brasil: um esquema analítico. Revista de Economia Política, v. 35, n. 4(141), p. 708-727, 2015.

SOUZA, F. E. P.; HOFF, C. R. O regime cambial brasileiro: sete anos de flutuação. Rede de Pesquisas do Mercosul, 2006.

\section{Sobre os autores}

Leandro Vieira Lima Araújo - leanvla@hotmail.com

Universidade Federal do Rio Grande do Sul, Porto Alegre, Rio Grande do Sul, Brasil.

ORCID: http://orcid.org/0000-0001-8947-9764.

Bolsista da CAPES, o que permitiu o financiamento da elaboração da pesquisa.

Fábio Henrique Bittes Terra - fhbterra@gmail.com

Universidade Federal do ABC; Programa de Pós-Graduação em Economia, São Bernardo do Campo, São Paulo, Brasil. ORCID: http://orcid.org/0000-0002-2747-7744.

Pesquisador do CNPq, a quem agradece o financiamento desta pesquisa.

\section{Sobre 0 artigo}

Recebido em 26 de agosto de 2016. Aprovado em 03 de abril de 2017. 